\title{
INCREASED MOTOR ACTIVITY FOR PREVENTION OF COMPLICATIONS IN THE ELDERLY WITH DIABETES
}

\author{
Ruska Paskaleva, Galina Mratzkova \\ Medical Faculty, Trakia University, Stara Zagora, Bulgaria
}

\begin{abstract}
The purpose of the present study is the active participation of the students of specialty "Medical rehabilitation and ergotherapy" in the implementation of rehabilitation activities at the Diabetes Center - Stara Zagora, in elderly people with type 2 diabetes. Material and methods. The subject of the study is 120 diabetic patients at the Diabetes Center Stara Zagora with different types of diabetes. Methodology of the study. Anthropometric measurements were performed, a specialized test for daily activities (DA Test, with a six-step assessment from 0 to 5) and a Quality of Life Test. The tests were applied to 120 diabetic patients before and after rehabilitation. Results and discussion. The correlation between influencing the physical and mental health of patients is positively significant $(R=0.61, p<0.05)$. This is an evidence of the incomparable influence of motor activity on the quality of life of diabetic patients. These results motivate the participation of students in the practical training, which is a factor that ensures the improvement of the quality in the real working environment. Conclusions and conclusions: The implementation of complex rehabilitation in patients with diabetes type 2 requires prolonged activities in specialized rehabilitation centers to stimulate motor activity and social integration; to achieve good results in the rehabilitation of diabetic patients and to improve self-care, it is essential to start early, to include work and training in self-sustaining activities from everyday life, Ergotherapy and art therapy stimulate patient autonomy.
\end{abstract}

Key words: motor activity, elderly people, diabetes, prevention of complications.

\section{INTRODUCTION}

The implementation of a complex rehabilitation in patients with type 2 diabetes requires continuing activities in specialized rehabilitation centers for stimulating motor activity and social integration. (Andonova, 2012; Vacheva, 2009) Early initiation is essential for achieving good results in the rehabilitation of diabetic patients and improving their ability to self-care (Vacheva, 2011), inclusion of work activities and training in self-sufficient activities of daily live, ergotherapy and art therapy (Dimitrova, 2008).

Ergotherapy is applied in the rehabilitation and re-socialization of elderly people with diabetes through various occupational activities and training in daily activities. It distracts elderly people's attention, diverting them away from various problems; it has an emotional effect through the different activities and contributes to building new skills. (Paskaleva, 2018; Kyuchukova, 2010; Trombly, 1996)

Art therapy is increasingly entering the lives of modern people - as a scientific field of knowledge, as an increasingly demanding practice with high impact efficiency and with multiple and diverse techniques of art therapy work, such as theory and methodolo- $\mathrm{gy}$, as a discipline in different educational institutions at different levels (Topuzov, 2006; Topuzov 2009).

Exercise and sports are used in the prevention and treatment of elderly people with diabetes. Their versatile healing effect and prophylactic effect counteracts premature aging, keeping the aging body at the highest structural and functional level possible. The group form of activity is recommended, but in the absence of such an opportunity, adults can also practice independently, given in advance the necessary instructions for self-control and proper exercise. (Koleva, 2009; Koleva, 2008)

Elderly people with diabetes needs to change their lifestyle towards performing moderate exercise, eating properly, monitoring their blood sugar levels, and maintaining the emotional tone of the patient. This is achieved by improving the quality of life of diabetic patients.

I. Topuzov (2006) defines the quality of life as a synthesis of the standard of living, personal interests and their implementation in the lifestyle (Yancheva, 1998). 
Quality of life is a measurable concept that includes: the standard of living, the personal interests of the individual and their realization in lifestyle. The standard of living is determined by quantitative biological, social and economic dimensions of life. It is a measurable assessment of health, material, intellectual and formal interests. Personal interests reflect the qualitative and psychosocial dimensions of life. They assess the degree of satisfaction that an individual experiences from intellectual, cultural, aesthetic and moral values (Sinaki, 1987; Titianova, et al 2012) .

Lifestyle is the individual complex of the standard of living and personal interests. It is influenced by the traditions in the country, the professed religion, the political system, the ideological and geographical conditions. As a collective expression of personality, the lifestyle is influenced by the bio-psychological characteristics of the individual (Peurala, 2005). According to contemporary authors in the field of Ergotherapy, the quality of life is a more important factor in the impact of the damage to the person than the damage itself. For assessing the quality of life are used: medical methods to evaluate and determine the patient's rehabilitation potential (Clinical Scale of Quality of Life in grades 1 to 3); psychological evaluation; sexual evaluation; sociological evaluation; practical evaluation and integrated evaluation of quality of life as a summary of other assessments (Paskaleva, Vacheva, 2019).

Improving the quality of life of elderly with diabetes is achieved through the complex approach of modern rehabilitation, including physical exercise, occupational activities in the form of ergotherapy and art-therapeutic activities.

The purpose of this development is to implement rehabilitation activities at the Diabetes Center-Stara Zagora for the elderly with type 2 diabetes.

\section{METHODOLOGY}

The object of the study is 120 diabetic patients at the community-social center "Diabetes" - Stara Zagora with type 2 diabetes. The sessions are conducted for one year with consecutive work in groups, twice a week by the students during the clinical practice.
Methodology of the study. Anthropometric measurements were performed, a specialized test for daily activities (a DA test, the six-step assessment from 0 to 5) and a test for quality of life (a test for quality of life in grades 1 to 3 ). The last one consists of four parts (1. Physical health and daily activities; 2. Psychological test and appearance; 3 . Social and personal relationships; 4 . Environment and financial resources), it gives a very accurate picture of the quality of life of patients with diabetes. The tests were administered to 120 diabetic patients before initiation and after completion of rehabilitation, grouped into five groups for rehabilitation depending on motor abilities. A Rehabilitation Program for all groups has been implemented within one calendar year with the voluntary and active participation of the students. The program includes: kinesitherapy (physical exercises with a large therapeutic ball and dosed walking), proper nutrition, ergotherapeutic activities (DA and functional ergotherapy) and art therapy (making souvenirs, cards, etc.).

The results of the tests were recorded in a specially developed map for diagnosis and rehabilitation of the patient, and the data from the study were processed with the statistical computer program STATGRAPHICS, WINDOWS, EXCEL and.

\section{RESULTS AND DISCUSSION}

The results achieved in improving daily activities (Figure 1) and gait stability confirm the thesis that exercising regular physical activity in patients with diabetes maintains good muscle condition, prevents the occurrence of complications in the nervous system and musculoskeletal apparatus. Prior to the procedures, the majority (59\%) of the patients tested were rated 2 and had difficulty in DA, and after the procedures (76\%), the patients had improved motor performance (grades $3+; 4$ and 5). indicative of the stimulating effect of kinesitherapy, ergotherapy and art therapy on the motor activity of patients. All of them have advanced motor skills in everyday activities, have become more confident in these activities and have developed creativity and art-therapeutic skills. 


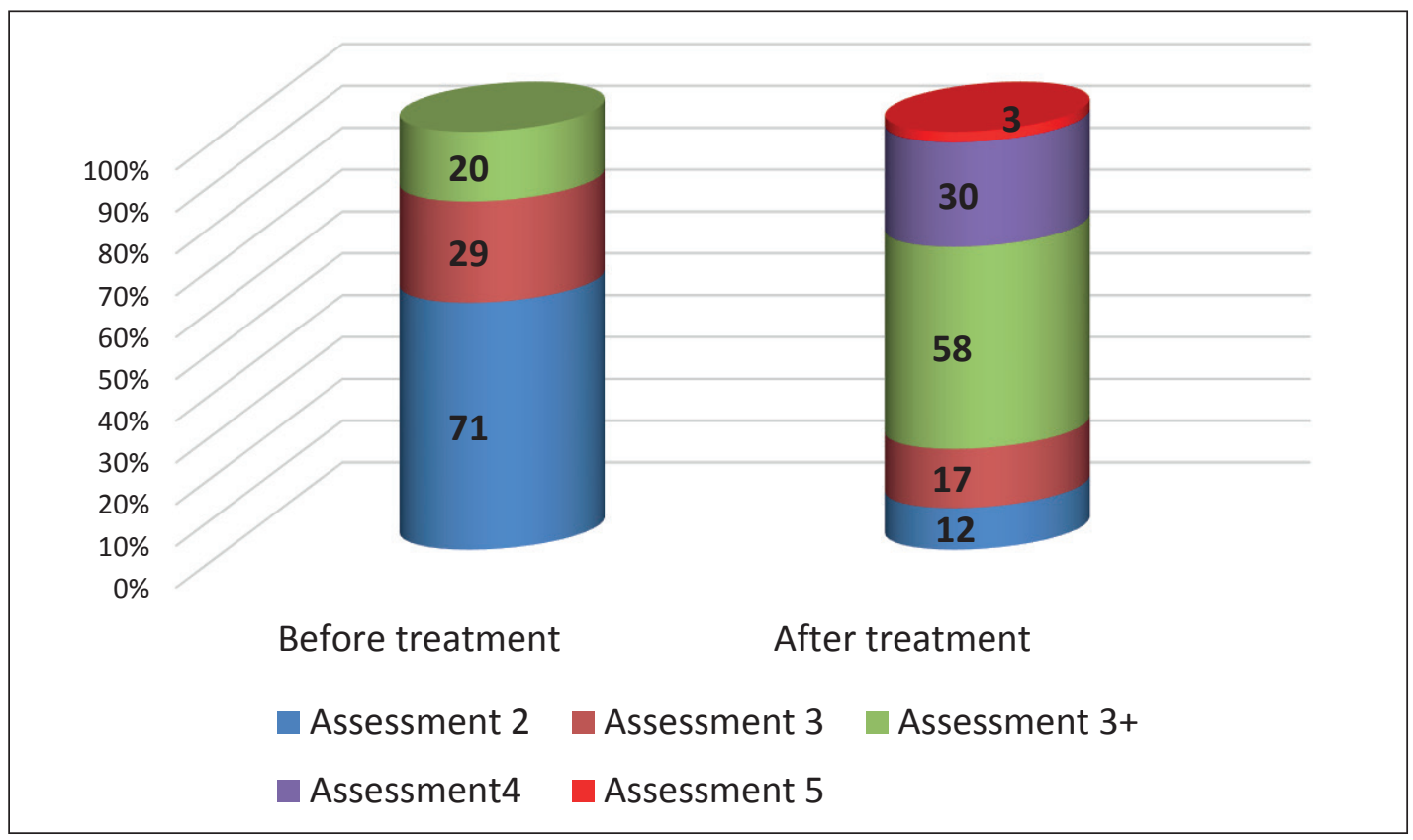

Figure 1. Results of the DLA improving before and after rehabilitation

This is evidence of the incomparable impact of motor activity on the quality of life of diabetic patients. These results also motivate students' participation in practical training, which is a factor ensuring quality improvement in the real work environment, guaranteeing the acquired professional competences and successful professional realization of students. The results of the DLA test for everyday domestic-professional activities for the lower limbs and stabilization of gait before and after rehabilitation (Figure 2) are indicative of the good effect of complex procedures on the balance and maintaining the balance of sitting and standing, walking evenly, on a slope, back and forth, climbing up and down stairs. Hy-square link test - the differences in the pre- and post-treatment assessments are highly statistically significant $(\mathrm{P}<0.001)$. This is evidence of the incomparable impact of motor activity on the quality of life of diabetic patients interacting with the right diet and social interactions at the community-social center "Diabetes" in Stara Zagora.

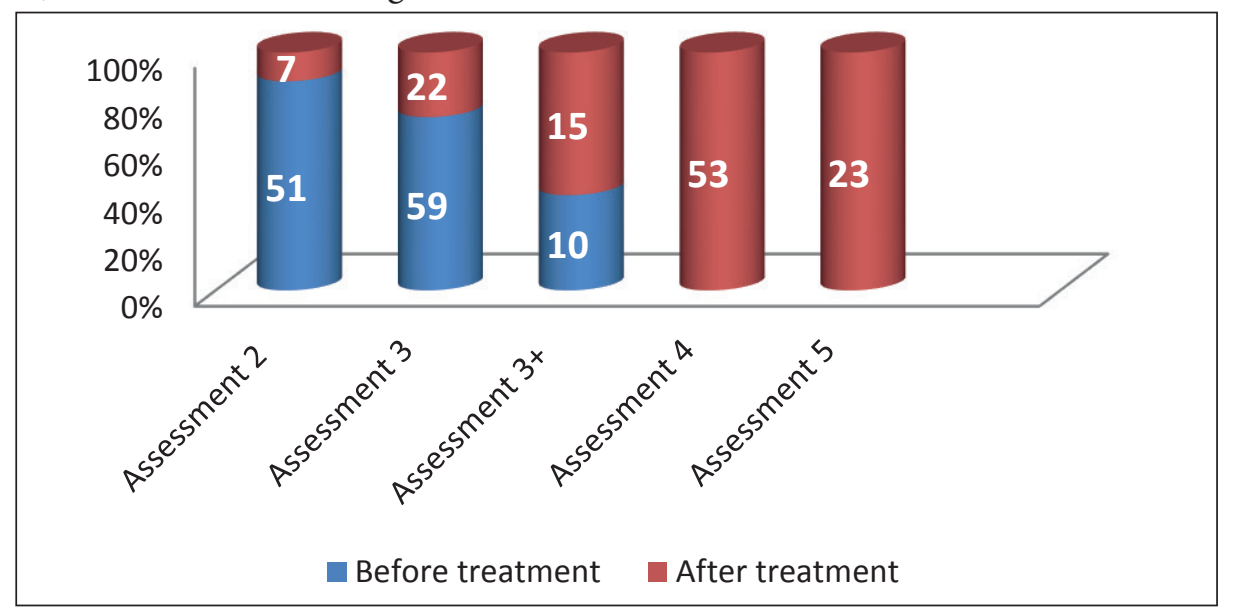

Figure 2. DLA test for everyday domestic-professional activities for the lower limbs and stabilization of gait before and after rehabilitation

In Figure 3. the results of the DLA test for every- cluding crossing of streets, use of private and public day domestic-professional activities related to travel transport (getting on and getting off), driving and before and after rehabilitation are presented, in- other motor activities. The joint events organized 
by community-social center "Diabetes" in Stara Zagora and the students in the specialty Medical Rehabilitation and Ergotherapy at the Faculty of Medicine at Trakia University stimulate and motivate elderly people with diabetes to a more active lifestyle and more social contacts. Culinary exhibitions and art therapy workshops are organized on the occasion of major Christian holidays with many guests and pleasant emotions.

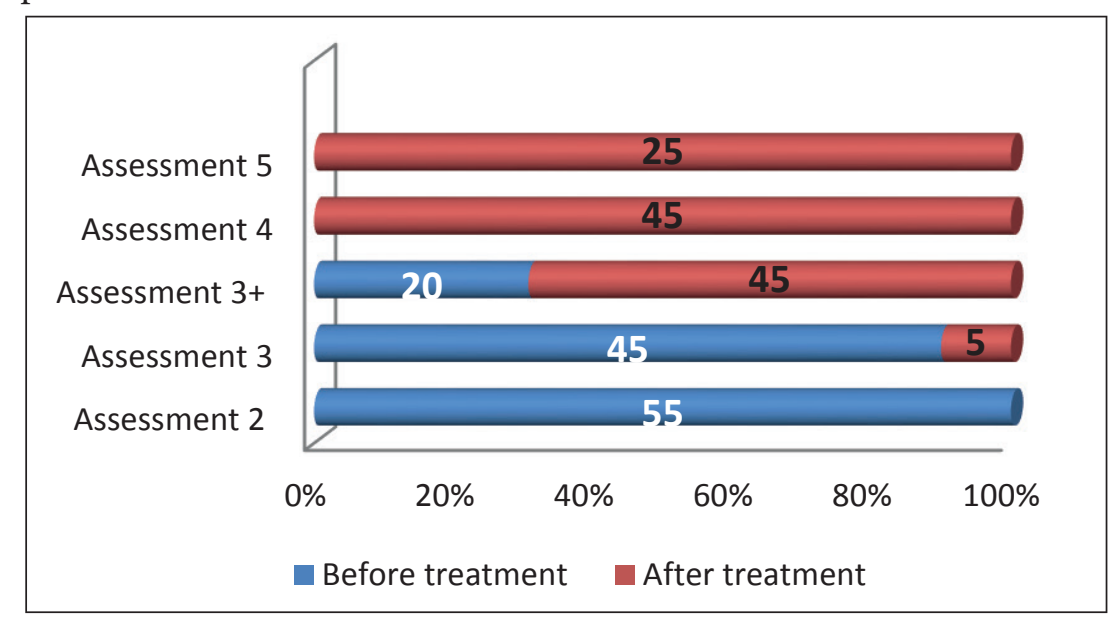

Figure 3. Results of the DLA test for everyday domestic-professional activities related to travel before and after rehabilitation

All these joint activities improve the quality of life of the elderly with diabetes and are voluntarily implemented by students (Kyuchukova, 2010; Mollova et al, 2017; Paskaleva, 2012).

Results from the Quality of Life Test: The correlation between patients' physical and mental health responses was direct, significant in strength and statistically significant $(R=0.61 ; p<0.05)$. This is evidence of the significant impact of rehabilitation activities and art therapy on the quality of life of adults with diabetes.

\section{FINDINGS AND CONCLUSIONS}

Exercising regular physical activity keeps the muscles in good condition, prevents the occurrence of inactive hypotrophies or contractures, and activates various types of modulating descending control (pain suppressant) to maintain the patient's emotional tone.

\section{REFERENCES}

Andonova, A. (2012). Future Medical Specialists for the Specificity of Working with the Elderly, Sofia, XXX Scientific and Technological Session "Contact 2012" - "The Interdisciplinary Idea in Action" 26.10.2012, TEMTO pp. 193- 195

Dimitrova, E. (2008). Muscle relaxation and stretching in manual therapy. NSA PRESS; Sofia; pp.223.
Karaneshev, G., Milcheva, D. (2011). Methods for diagnostics and research in the therapeutic physical exercise. Sofia, VIF, 1984.

Koleva, I. (2009). Ergotherapy - philosophy and principles. Prevention and Rehabilitation, 3, 1-2, pp.53-58.

Koleva, I. (2008). Functional assessment in medical rehabilitation and ergotherapy. A textbook for students in Medical Rehabilitation and Ergotherapy at the Medical University - Pleven. Sofia: RICK SIMEL, pp.154.

Kyuchukova, S. (2010a). The Challenges of Contemporary Ethics to Volunteer Students in the field of Health Care, Academic Journal of Management and Education, Volume VI (4), ISSN 1312-6121, Burgas, pp.268-271.

Kyuchukova, S. (2010b). Volunteering in the European Union, Nursing Journal, Issue 2-3/, ISSN 1310-7496, MU-Sofia, pp. 32-34.

Mollova, K., Albert, M., Filkova, S., Dzhurkova, R. (2017). Physical Activity in Elderly People with Osteoporosis - Proceedings of a Scientific Conference with International Participation "Aging, Health, Geriatric Care", pp. 189-194.

Paskaleva, R., Vacheva, D. (2019). Motivation of Students for Active Participation in Practical Training. Knowledge - International Journal, Vol.30.2 March, pp. 379-383

Paskaleva, R. (2017). Application of occupational therapy and kinesitherapy to improve the driving activity and activities of daily life (ADL) in children with cerebral damage. Medicine \& Science in Sports \& Exercise, Issue 12 (2), (December), Volume 49. Lippincott Williams \& 
Wilkins Ltd. Pp. 2875-2884.

Paskaleva, R. (2018). Increasing the motivation of students for practical work through motor activity and prevention of complications in elderly people with diabetes. KNOWLEDGE - International Journal, Vol 23.1, pp. 519525.

Paskaleva, R. (2012). Innovative Elements in the Training of Kinesitherapy, Art Therapy and Ergotherapy for Rehabilitation Students. Monograph, Publishing House EKSPRES - Gabrovo, pp. 120.

Peurala, Sinikka, H. (2005) Rehabilitation of Gait in Chronic Stroke Patients. Series of Reports, No 74, Department of Neurology, University of Kuopio, pp.108.

Platikanova, M. (2015). Working conditions, labour organisation and musculoskeletal and optical systemrelated complaints when working with video displays. International scientific on-line journal "Science \& Technologies"; V (1) pp.184-189.

Platikanova, M., Slavova, V., Ivanov, V., Alekova, S. (2015). Role of neuro-psychlogical tension and fatigue in the daily activites of general practition from the Stara Zagora region. Trakia Journal of Sciences; 13 (2) pp.180183.

Vacheva, D. (2009). Types of grips and their testing for various injuries and diseases of the hand. Neurorehabilitation, Volume 3, 1-2, pp.26-31.

Vacheva, D. (2011). Reporting of the restoration of activities of daily living (toilet and personal hygiene) in patients with consequences of cerebrovascular disease. Neurorehabilitation, Volume 5, 2, pp.68-69.

Sinaki, M. (1987). Basic clinical rehabilitation medicine. Toronto - Philadelphia, W. B. Saunders Co.

Titianova, E., Chamova, T., Karakaneva, S., Dimova, R. (2012). Myosonographic Assessment of Triceps Surae Muscle in Chronic Post-Stroke Hemiparesis. Neurosonology And Cerebral Hemodynamics, vol. 2, pp. 75-80. Topuzov, I. (2006). Ergotherapy. First part. Sofia, REC Simel.

Topuzov, I. (2009). Ergotherapy. Third part. Sofia, REC Simel.

Trombly, CA. (1996). Occupational Therapy for Physical Dysfunction. - Boston - Baltimor - Philadelphia Hong-Kong - London - New York - Sydney - Tokyo: Williams \& Wilkins.

Yancheva, S., Milanov, I., Georgiev, D., Shotekov, P. (1998). Motor activity.

Neurology - General neurology. Ed. by Prof. Yancheva. Stara Zagora, Knowledge.

\section{Corresponding authors: Ruska Paskaleva}

Department of Medical Rehabilitation and Ergotherapy, Physical Medicine and Sports

Medical Faculty, Trakia University,

Stara Zagora, Bulgaria

E-mail: ruska.paskaleva@trakia-uni.bg 